beyond a first-year course. The writer confesses to a feeling of disappointment that the structural work on minerals carried out so strenuously in the last 25 years finds practically no place in this introduction to the subject.

Department of Physics

G. W. BRINDLEY

The University

Leeds, England

Gmelin Handbuch der anorganischen Chemie. Selen B 2: Die Verbindungen des Selens. Pp. xxviii +195 . Clausthal-Zellerfeld: Gmelin-Verlag. 8th ed. 1949. Price DM.40*60.

This handbook claims to be based on about 1900 journals, and on standard works such as the International Critical Tables, Landolt Börnstein Tabellen, Strukturberichte and the Tables Annuelles, up to 1 January 1948.

In addition to a description of the chemical properties of various compounds, a comprehensive account is given of important physico-chemical data. These include properties of the solid state such as data for crystal chemistry, thermal transformations in the solid, vapour pressure, entropy of fusion, molar heat capacity, coefficient of expansion, and solubility in various solvents. Special properties such as the electrical conductivity, photosensitivity and magnetic susceptibility of mixed crystals of $\mathrm{Se} / \mathrm{S}$ are also included where relevant.

The standard achieved for the section on selenium compounds is high and if it can be maintained the eighth edition of this handbook should be even more valuable than its predocessors for workers in inorganic and physical chemistry, and in various branches of chemical physics.

The Queen's University

Belfast

Northern Ireland

Crystals and X-rays. By K. Lonsdale. Pp. viii + 99, with 138 figs. and 13 plates. London: G. Bell and Sons, Ltd. 1948. Price 21s.

This little book is divided into seven chapters: I, Historical Introduction. II, Generation and Properties of X-rays. III, The Geometry of Crystals: X-ray Methods of Investigation. IV, Geometrical Structure Determination. $V$, Determination of Atomic and Electronic Distribution. VI, Extra-structural Studies. VII, The Importance of the Study of Crystals.

In the foreword, the author says that the book 'is not a textbook for advanced students of X-ray crystallography', but, rather, 'is designed to interest those who do not now use X-ray crystallography but who might well do so', and to inspire those who have had the tool of X-ray diffraction put into their hands to use it more intelligently. The book is based on a series of public lectures given by the author at University College, London.

For the scientist not versed in X-ray crystallography, perhaps the most important chapter is the comparatively non-technical 'Historical Introduction'. In this chapter the author not only sketches the history of the development of X-rays and X-ray diffraction, but gives a nicely balanced view of the place of X-rays in modern science. When the evidence is assembled, the debt modern science owes to X-rays and X-ray diffraction is striking indeed. In the reviewer's opinion, this chapter is beautifully done and should be read by all scientists.

The remainder of the book comprises a selection of topics treated in a manner which the author feels best fulfils her desire to represent $X$-rays and $X$-ray crystallography to the scientist not versed in this particular field, and to the industrial administrator. The subject-matter should certainly prove stimulating to the scientist, but may be somewhat abstruse at times to the administrator. But if it is abstruse, it at least well represents the remarkable things which can be done with $\mathrm{X}$-rays for industry in the hands of a skilled investigator.

The veteran $\mathrm{X}$-ray crystallographer will probably find that a good deal of the book is a discussion of material quite familiar to him. Yet almost every reader will find a scattering of this subject matter which appears in novel and stimulating form. The penultimate chapter on ' Extrastructural Studies' should be interesting to nearly everyone. It includes particularly engaging treatments of primary and secondary extinction and vibrations of atoms in crystals.

M. J. BUERGER

\section{Department of Geology}

Massachusetts Institute of Technology

Cambridge 39, Mass., U.S.A.

\section{Theory of Groups and its Application to Physical}

Problems. By S. Bhagavantam and T. Venkatarayudu. Pp. 234. Waltair: Andhra University. 1948. Price $\mathbf{R} 20$.

Despite the great variety of physical subjects to which group-theoretical methods can be applied with advantage, the methods are not widely understood, and even many who use then possess no more than a working knowledge of the technique. Partly, no doubt, this is due to the inadequacy of general literature on the subject, particularly in the English language. Every new book in this field is therefore an important addition. The substance and general plan of the book by Bhagavantam and Venkatarayudu leave very little to be desired. The range of subjects covered is more extensive than to be found in any other single treatise. Besides the application to atomic spectra and the vibrational, rotational and Raman spectra of molecules, there is much material of special interest, such as, for instance, the discussion in Chapter $\mathrm{XI}$ of the external and internal oscillations of molecules in crystals, the method given in Chapter XVI of determining the number of permissible (by symmetry) independent constants involved in various covariant physical quantities relating to single crystals (elastic constants, photo-elastic constants, etc.). As to the general plan of the book, the authors have wisely made the mathematical preliminaries short so that the reader's interest is roused by the physical applications, before his patience is overtaxed by purely mathematical developments.

Although intended primarily for readers new to the subject, the text of the book is by no means easy to follow. Though the clarity of the exposition is often admirable, the explanations, particularly as regards the more basic points, are not always sufficient for a clear understanding of the issue. In compressing so much matter in a volume of this moderate size, such difficulties are perhaps not altogether avoidable. However, they are no doubt at 
times accentuated by the occasional lack of accuracy or precision in the treatment. For instance, the orthogonality of the transformation between the symmetry co-ordinates and $\sqrt{ } m_{k}$ times the Cartesian co-ordinates (not Cartesian co-ordinates themselves, cf. p. 57) is not always correctly applied. In this way errors are apparently caused, such as in the normal co-ordinates given on p. 76 (translational normal co-ordinates should always be the displacements of the centre of mass), and the obvious discrepancy in physical dimensions of the displacements given in the table on the same page and in the Hamiltonian function given on the next. The scarcity of references to original works and the equations being unnumbered are minor points that might also be regretted.

In Chapter $x$ the authors discuss at some length the different views held by Born and Raman regarding the optical branch of crystal vibrations, and refute Born's theory. To the reviewer's mind, such a controversial subject would best be left out of a book designed chiefly to illustrate the group-theoretical method. The theoretical arguments which follow a rather confused pattern do not strictly lead to any definite conclusions, in spite of the authors' claims. Actually there are only two points for discussion, namely, the possible solutions of the equations of motion and the boundary conditions. As the general solutions of the lattice motion are exactly known and well understood by anyone familiar with wave motions, the qualitative arguments given by the authors about imaginary displacements are unnecessarily mystifying. As regards the boundary conditions, evidently nothing can be achieved by qualitative arguments in view of Ledermann's proof that the frequency distribution is independent of boundary conditions. (In connexion with the experiments quoted by the authors, it may be of interest to mention that a manuscript has just come to the reviewer describing some accurate intensity measurements by Welsh, Crawford \& Staple on the Raman spectrum of $\mathrm{NaCl}$. The resolving power of the experimental set-up is three times that of the most accurate experiments by Krishnan; the results fully confirm Born's theory as worked out explicitly by Born \& Bradburn. The observed maxima are too broad to be discrete lines and even the strongest line is only $50 \%$ above the continuum intensity.)

Several chapters of the book are devoted to crystals. The general ideas of the space groups are somewhat sketchily developed in Chapters II and XI. No application of group representation theory peculiar to space groups is given in the book; for the authors consider only the Raman vibrations which can all be described in terms of waves with infinite wave lengths, if the elementary cell is taken as eight times the real elementary cell of the lattice. Such vibrations of infinite wave lengths are well known to be equivalent to vibrations of a molecule containing as many atoms as there are atoms in the crystal elementary cell. For the designation of the point groups and space groups the authors use the older Schoenflies notations which are usually replaced by the more rational MauguinHermann notations in the more recent publications on space groups.

On the whole it is safe to say that every physicist interested in knowing the broadest aspect of the applications of group theory to physics will find the book with its large number of actual examples over a wide range of subjects, and presented with considerable details, a treatise both useful and stimulating.

K. HuANG

The University

Liverpool

England

\section{Books Received}

The undermentioned works have been received by the Editors. Mention here does not preclude review at a later date.

The Optical Principles of the Diffraction of X-rays. By R. W. JAMES, being vol. II of The Crystalline State. Pp. xv +623 , with 224 figs. London: G. Bell and Sons, Ltd. 1948. Price 80s.

Probleme der Naturwissenschaften. By P. NigGLI. Pp. 240, with 100 figs. Basel: Birkhäuser. 1949. Price 18.50 Swiss francs.

Einführung in die Mineralogie (Kristallographie und Petrologie). By C. W. Correns. Pp. 414, with 405 figs. Berlin: Springer. 1949. Price DM. 38.00; bound DM. $41 \cdot 60$.

Mineralogische Tabellen. By H. Strunz. Pp. xiv +308 , with 73 figs. Leipzig: Akademische Verlagsgesellschaft Geest und Portig K.-G. 1949. Price DM. 21·00.

Gmelin Handbuch der anorganischen Chemie. Antimon B2. Pp. 368+xiv. Clausthal-Zellerfeld: Gmelin-Verlag. 1949. Price DM. 83.60.

Gmelin Handbuch der anorganischen Chemie. Antimon B3. Pp. $69+$ xliv, with 4 figs. ClausthalZellerfeld: Gmelin-Verlag. 1949. Price DM. 24·75.
Gmelin Handbuch der anorganischen Chemie. Platin $A 5$. Pp. $188+$ viii, with 61 figs. ClausthalZellerfeld: Gmelin-Verlag. 1949. Price DM. 43.00.

Materiewellen und ihre Interferenzen. By M. voN LaUt. Pp. viii +392, with 156 figs. Leipzig: Akademische Verlagsgesellschaft Geest und Portig K.-G. 1948. Price DM. 34.00.

Materialprüfung mit Röntgenstrahlen unter besonderer Berücksichtigung der Röntgenmetallkunde. By R. GlockER. Pp. viii +440 , with 349 figs. Berlin, Göttingen and Heidelberg: Springer. 3rd ed. 1949.

On the Systems formed by Points Regularly Distributed on a Plane or in Space. By M. A. Bravais, translated by Amos J. ShaLER from Journal de l'École Polytechnique (1850), 19, 1, being Memoir No. 1 of the Crystallographic Society of America. Obtainable through the Secretary-Treasurer Dr W. Parrish, Philips Laboratories, Inc., Irvington-onHudson, New York, U.S.A. Pp. viii +113 , with 41 figs. 1949. Price $\$ 3 \cdot 90$. 